University of South Carolina

Scholar Commons

7-1996

\title{
Student Perceptions, Values, and Beliefs Prior to, During, and After Badminton Instruction
}

Bonnie L. Tjeerdsma

Georgia State University

Judith E. Rink

University of South Carolina - Columbia, jrink@mailbox.sc.edu

Kathy C. Graham

Follow this and additional works at: https://scholarcommons.sc.edu/pedu_facpub

Part of the Education Commons

\section{Publication Info}

Published in Journal of Teaching in Physical Education, Volume 15, Issue 4, 1996, pages 464-476. http://journals.humankinetics.com/jtpe-contents (C) 1996 by Human Kinetics Publishers

This Article is brought to you by the Physical Education, Department of at Scholar Commons. It has been accepted for inclusion in Faculty Publications by an authorized administrator of Scholar Commons. For more information, please contact digres@mailbox.sc.edu. 


\section{Student Perceptions, Values, and Beliefs Prior to, During, and After Badminton Instruction}

\author{
Bonnie L. Tjeerdsma \\ Georgia State University
}

\author{
Judith E. Rink, Kathy C. Graham \\ University of South Carolina
}

Affective goals for physical education have historically been an identified goal for physical education programs, and such goals continue to be integral parts of what physical education teachers say they want to do. Affective value orientations to curriculum have also been identified as strong aspects of the values and belief systems of practicing physical educators (Ennis, Ross, \& Chen, 1992) as well as the values and belief systems of preservice teachers (Solmon \& Ashy, 1995).

The national standards for physical education (National Association for Sport and Physical Education [NASPE], 1995) identify seven standards that students should achieve as a result of a comprehensive physical education program. According to these standards, a physically educated person

1. Demonstrates competency in many and proficiency in a few movement forms.

2. Applies movement concepts and principles to the learning and development of motor skills.

3. Exhibits a physically active lifestyle.

4. Achieves and maintains a health-enhancing level of physical fitness.

5. Demonstrates responsible personal and social behavior in physical activity settings.

6. Demonstrates understanding and respect for differences among people in physical activity settings.

7. Understands that physical activity provides opportunities for enjoyment, challenge, self-expression, and social interaction. (NASPE, 1995, p. 1)

Three of these standards are affective. The last standard in particular is unique to the role of the physical educator and is designed to develop an awareness of the intrinsic values and benefits of physical activity. Students who develop positive attitudes toward physical activity and who are aware of the benefits of participation have a greater chance of developing and maintaining an active lifestyle. The intent of the standards is to identify the critical role affect should play in teaching physical education. Affective learning is not disconnected from the traditional content of physical education, but is a critical aspect of teaching that content. For instance, it would be important for students, regardless of the content or the process of instruction, to find the experience personally meaningful. In this sense, affective goals are part of the organic curriculum (Glatthorn, 1994): those goals that are of high importance but low structure. 
Research on the attitudes of students toward physical education is scant but remarkably consistent. The work indicates that it is the curriculum content itself which is a primary determinant of student attitudes toward what we do, that is, the specific movement form or content (e.g., basketball, fitness) (Figley, 1985; Luke $\&$ Sinclair, 1991). The content that receives the most positive ratings from secondary students is sport, with team sports and individual and dual sports ranked highest (Figley, 1985; Luke \& Sinclair, 1991; Tannehill \& Zakrajsek, 1993).

Unfortunately, there has not been a great deal of research in physical education supporting the differential effects of varying curricula and different instructional orientations on affective outcomes. There is some support for the idea that different instructional orientations do effect student affect and different affective goals can be taught. Work done by Goldberger, Gerney, and Chamberlin (1982) found that the reciprocal style resulted in significantly more social development. In other teaching intervention studies where affective change was assessed, the results for all treatment groups were positive, but little difference between treatments was noted for affective outcomes (Harrison, Fellingham, Buck, \& Pellett, 1995; Rink, Werner, Hohn, Ward, \& Timmermans, 1985). Knowing the affective products of different instructional orientations is a critical dimension of building a knowledge base for pedagogy.

Studies done with the values orientations of teachers, both in-service and preservice, demonstrate that teachers and would-be teachers see teaching affect as a critical part of their work. Work by Ennis and her colleagues (Ennis, Chen, \& Ross, 1992; Ennis et al., 1992; Ennis \& Zhu, 1991) on value profiles of practicing teachers clearly demonstrates that practicing teachers differ in the emphasis they put on different goal orientations for their programs. This emphasis is largely not an orientation toward the traditional content of physical education. The work of Ennis and her colleagues suggests that the teachers studied put a high priority on the more affective standards developed by NASPE (1995) rather than the initial four standards. Solmon and Ashy's (1995) work reflects a similar pattern for inservice teachers who come into teacher education programs with a propensity toward more affective goals. The concern of many teacher educators has been that practicing teachers may have abandoned a focus on the curriculum goals most associated with teaching content (Standards 1-4 above) for more affective concerns, particularly those curricular orientations related to developing self-actualization (individual development and growth) and social reconstruction (improving society).

Given the importance physical education teachers attach to affective program goals, it is imperative that researchers study the effects of different content and teaching approaches on the affective development of students. The purpose of this part of the badminton research project was to determine (a) the attitudes of students coming into the project toward sport in general and badminton in particular, and (b) the effects of the different teaching approaches on the students' attitudes and perceptions of the class and themselves as participants. The units of both of these studies (French, Werner, Rink, Taylor, \& Hussey, 1996; French, Werner, Taylor, Hussey, \& Jones, 1996) were taught with a content mastery intent (Glatthorn, 1994). Students were interviewed at three different times in the 6-week study. At the preunit interviews, researchers were interested in student attitudes toward sport in general and badminton as a sport in particular. At the midunit and postunit inter- 
views, researchers were interested in documenting changes that may have taken place since the beginning of the study, as well as student attitudes and perceptions of their experiences in the different instructional groups (skill, tactics, or combination).

\section{Methods}

\section{Subjects and Setting}

Complete data were collected on 44 students who took part in the 6-week study (French, Werner, Taylor, et al., 1996). The students in the experimental groups (skill, tactical, and combination) were interviewed prior to the study (preunit), at the 3-week midpoint of the study (midunit), and at the end of the 6-week study (postunit). The control group was interviewed prior to and at the end of the 6-week study, but not at the midunit point.

\section{Interview Protocol}

The interview protocol was designed to allow collection of information on several dimensions of student attitudes and perceptions. The preunit interview included both closed and open-ended questions describing student perceptions of their enjoyment of, ability in, and reasons for participating in both sport in general and badminton in particular.

The midunit interview asked students to talk about whether they were better, the same, or worse at badminton than they were before the unit began. Researchers also asked students at the midunit to describe how they thought they were better/ not better and why they thought they were better/not better. The midunit interviews concluded with questions about the physical education class students were in.

At the postunit interview, students were asked the same questions that were part of the preunit and midunit interviews. In addition, the students were asked if they planned to play badminton again in the future, if they liked physical education classes that tried to teach them something, and whether they preferred 3- or 6week units. They were then asked to provide reasons for their responses. The students were also asked how this physical education class differed from their previous physical education classes.

For some of the questions, students were asked to respond to a Likert rating scale followed by interviewer follow-up questions. Six-point Likert scales ranging from not at all or poor (1) to very much or very good (6) were used to obtain information on student enjoyment of sports and badminton, the importance of sports and badminton, and student perceived ability at sports and badminton. After selecting a Likert scale response, students were then asked to provide reasons for choosing a particular rating for each question.

\section{Procedures}

The interview protocols were pilot-tested with 10 ninth-grade students from the school where the 6-week study was conducted, but who were not participating in the study. Adjustments were made to the protocols based on the pilot test. Five professors and graduate students were trained to conduct the interviews. None of the three teachers who taught the badminton units participated in the interviews. 
The students were interviewed individually and privately in classrooms as part of the testing dates prior to the unit, at the midpoint of the unit, and at the end of the unit. Students were told that all information they supplied the interviewer would be treated confidentially. The interviewers recorded the students' answers verbatim on the interview form. Each interview averaged about 20 minutes.

\section{Data Analyses}

A series of $4 \times 2 \times 2$ (Group $\times$ Gender $\times$ Preunit/Postunit) ANOVAs with repeated measures on the last factor were used to analyze the Likert scale ratings of students' enjoyment of sports and badminton, the importance of sports and badminton, and student's perceived ability at sports and badminton. A significance level of $p<.05$ was chosen for all analyses.

All open-ended responses were analyzed by two of the researchers in a series of steps utilizing the methods of inductive analysis and constant comparison (Lincoln \& Guba, 1985). First, they separately examined the responses, sorting units of data into initial categories. Second, they compared their original categories and inclusion rules and produced a mutually agreed upon set of categories and rules. Categories that were common to the investigators' initial sets were retained. Discrepancies between their original categories were discussed and refined, producing new categories that were added to the analysis set. Third, the two investigators again separately examined the open-ended responses, placing the data units into the new set of categories. Finally, the researchers compared their separate categorizations of the open-ended responses. Discrepancies between the investigators regarding proper categorization of units were discussed until 100\% agreement was reached. Frequency counts by gender, group, and interview (preunit, midunit, or postunit, if the question was asked in more than one interview) were recorded for the categories of each question.

\section{Results}

The results of this study are discussed first in terms of the Likert scale responses and then in terms of the open responses given to general questions regarding sport and badminton specifically. The Likert scale group means and frequencies for open responses for each of the groups are presented in Table 1. The midunit interview data and the breakdown of the data by gender are not presented in the table because of space limitations but are reported in the text.

\section{Likert Scale Ratings}

Only one significant result was found in the three-way ANOVAs on the Likert scale ratings. The students' ratings of their badminton ability were higher after the 6 -week badminton unit $(M=4.41)$ than before $(M=4.02), F(1,38)=5.75, p<.03$. This difference from pre- to postunit appears to be primarily due to the experimental groups, as each of their mean Likert scale ratings increased slightly (skill, preunit $M=4.33$, postunit $M=4.40$; tactical preunit $M=4.00$, postunit $M=4.42$; combination preunit $M=4.20$, postunit $M=4.90$ ), whereas the control group decreased (control preunit $M=3.64$, postunit $M=3.50$ ). 


\begin{tabular}{|c|c|c|c|c|c|c|c|c|c|c|}
\hline \multirow[b]{2}{*}{ Question } & \multicolumn{4}{|c|}{ Preunit } & \multicolumn{6}{|c|}{ Postunit } \\
\hline & Con. & Skill & Tact. & Comb. & Total & Con. & Skill & Tact. & Comb. & Total \\
\hline Do you enjoy participating in sports? & 5.25 & 4.20 & 4.92 & 5.20 & & 5.50 & 4.30 & 4.83 & 5.20 & \\
\hline \multicolumn{11}{|l|}{ What do you enjoy participating in sports? } \\
\hline Sports are fun/like sports & 5 & 6 & 3 & 8 & 22 & 5 & 3 & 4 & 7 & 19 \\
\hline Social benefits & 2 & 3 & 2 & 1 & 8 & 1 & 2 & 0 & 3 & 6 \\
\hline Exercise/health benefits & 2 & 0 & 1 & 2 & 5 & 5 & 0 & 1 & 2 & 8 \\
\hline Competition/challenge & 3 & 1 & 3 & 1 & 8 & 2 & 0 & 1 & 0 & 3 \\
\hline \multicolumn{11}{|l|}{ Why don't you enjoy participating in sports } \\
\hline Low ability & 1 & 1 & 1 & 0 & 3 & 1 & 0 & 1 & 0 & 2 \\
\hline Is participating in sports important to you? & 4.92 & 4.30 & 4.09 & 4.20 & & 4.83 & 4.30 & 3.75 & 4.90 & \\
\hline \multicolumn{11}{|l|}{ Why is participating in sports important to you? } \\
\hline Health/exercise/fitness & 5 & 6 & 4 & 3 & 18 & 4 & 3 & 3 & 5 & 15 \\
\hline Fun & 2 & 1 & 0 & 2 & 5 & 6 & 1 & 0 & 1 & 8 \\
\hline Keeps me busy/helps time pass (something to do) & 2 & 0 & 2 & 1 & 5 & 2 & 1 & 3 & 0 & 6 \\
\hline Social/teamwork & 2 & 1 & 1 & 2 & 6 & 2 & 1 & 0 & 0 & 3 \\
\hline \multicolumn{11}{|l|}{ Not important to you? } \\
\hline Other things more important (relative value is low) & 0 & 0 & 3 & 1 & 4 & 1 & 2 & 1 & 0 & 4 \\
\hline Do you enjoy playing badminton & 4.50 & 5.00 & 4.91 & 4.40 & & 4.50 & 5.10 & 5.0 & 5.0 & \\
\hline \multicolumn{11}{|l|}{ Why do you enjoy playing badminton? } \\
\hline Like it/fun sport & 4 & 4 & 3 & 2 & 13 & 4 & 5 & 3 & 5 & 17 \\
\hline Similar to other sports & 2 & 2 & 1 & 3 & 8 & 0 & 2 & 1 & 2 & 5 \\
\hline Like the skills/strategy/purpose of the game & 1 & 1 & 2 & 2 & 6 & 0 & 4 & 5 & 4 & 13 \\
\hline Challenge & 2 & 1 & 1 & 1 & 5 & 1 & 1 & 3 & 0 & 5 \\
\hline Social aspects & 2 & 2 & 1 & 0 & 5 & 1 & 1 & 0 & 4 & 6 \\
\hline Learned from teacher & 0 & 0 & 0 & 0 & 0 & 0 & 0 & 0 & 3 & 3 \\
\hline \multicolumn{11}{|l|}{ What do you not enjoy playing badminton? } \\
\hline Little experience with the sport & 1 & 0 & 2 & 1 & 4 & 1 & 0 & 0 & 0 & 1 \\
\hline Low ability (didn't know skills/strategies) & 1 & 0 & 0 & 2 & 3 & 2 & 0 & 0 & 0 & 2 \\
\hline Didn't like the skills/strategy & 1 & 0 & 0 & 1 & 2 & 2 & 0 & 0 & 0 & 2 \\
\hline
\end{tabular}


Like it/fun

Social aspect

Have high ability

Fitness aaspect

Why is badminton not important to you?

Lack experience (haven't played it much)

Other things more important (low relative)

Low ability

How good are you at sports?

Why are you good at sports?

Effort (try hard/focus)

High natural ability

Lots of experience with sports (play them a lot)

High motivation/like it

Why aren't you good at sports?

Lack natural ability

Lack experience with sports

How good are you at badminton?

Why are you good at badminton?

High natural ability

Experience/played/practiced it

Learned from the teacher

High effort (worked at it)

Easy sport

Why are you not good at badminton?

Little experience (haven't played it/practice)

Lack skills (low ability)

Why are you better at badminton than you were

$\begin{array}{llll}3.20 & 3.11 & 2.73 & 3.90 \\ 4 & 1 & 2 & 2 \\ 2 & 1 & 0 & 0 \\ 0 & 0 & 0 & 0 \\ 1 & 0 & 0 & 0 \\ & & & \\ 1 & 1 & 3 & 2 \\ 1 & 2 & 3 & 1 \\ 0 & 0 & 0 & 0 \\ 4.42 & 4.00 & 4.08 & 4.20\end{array}$

$3 / 6$ weeks ago?

Mid 3 weeks ago:

Experience (opportunity to play/practice in class) Learned in class/taught by teacher

$\begin{array}{lllll}4 & 3 & 2 & 2 & 11 \\ 2 & 2 & 3 & 1 & \\ 2 & 2 & 1 & 3 & \\ 1 & 0 & 2 & 2 & \\ & & & & \\ 1 & 2 & 1 & 2 & \\ 1 & 0 & 0 & 0 & \\ 3.64 & 4.33 & 4.00 & 4.20 & \\ 4 & 3 & 4 & 3 & 1 \\ 2 & 2 & 4 & 3 & 11 \\ 0 & 0 & 0 & 0 & \\ 0 & 1 & 0 & 0 & \\ 1 & 1 & 1 & 1 & \\ & & & & \\ 2 & 3 & 2 & 3 & \end{array}$

\begin{tabular}{|c|c|c|c|}
\hline 2.67 & 2.90 & 3.09 & 3.90 \\
\hline 2 & 2 & 2 & 5 \\
\hline 0 & 1 & 0 & 0 \\
\hline 1 & 0 & 1 & 1 \\
\hline 0 & 0 & 1 & 1 \\
\hline 5 & 1 & 1 & 0 \\
\hline 3 & 3 & 3 & 2 \\
\hline 2 & 0 & 0 & 0 \\
\hline 4.50 & 4.20 & 4.25 & 4.70 \\
\hline 5 & 2 & 3 & 2 \\
\hline 5 & 4 & 2 & 2 \\
\hline 2 & 5 & 3 & 2 \\
\hline 3 & 0 & 0 & 2 \\
\hline 1 & 0 & 0 & 0 \\
\hline 0 & 0 & 0 & 2 \\
\hline 3.50 & 4.40 & 4.42 & 4.90 \\
\hline 2 & 5 & 4 & 2 \\
\hline 1 & 0 & 3 & 3 \\
\hline 0 & 2 & 3 & 4 \\
\hline 1 & 2 & 1 & 1 \\
\hline 0 & 0 & 0 & 1 \\
\hline 6 & 0 & 0 & 1 \\
\hline 1 & 0 & 2 & 1 \\
\hline
\end{tabular}


Table 1 Continued

\begin{tabular}{|c|c|c|c|c|c|c|c|c|c|c|}
\hline \multirow[b]{2}{*}{ Question } & \multicolumn{4}{|c|}{ Preunit } & \multicolumn{6}{|c|}{ Postunit } \\
\hline & Con. & Skill & Tact. & Comb. & Total & Con. & Skill & Tact. & Comb. & Total \\
\hline \multicolumn{11}{|l|}{ Post 6 weeks ago: } \\
\hline $\begin{array}{l}\text { Exerperience (opportunity to play/practice in } \\
\text { class) }\end{array}$ & & & & & & & 2 & 0 & 1 & 3 \\
\hline Learned in class/taught by teacher & & & & & & & 2 & 4 & 2 & 8 \\
\hline \multicolumn{11}{|c|}{ What did/do you like about the badminton class? $-3 \mathrm{wks}$} \\
\hline Competition/game play & & 4 & 3 & 5 & 12 & & 4 & 6 & 6 & 16 \\
\hline Social aspects (being with friends) & & 4 & 3 & 3 & 10 & & 4 & 1 & 2 & 7 \\
\hline Badminton is fun/like it & & 4 & 3 & 3 & 10 & & 3 & 3 & 1 & 7 \\
\hline Teacher & & 2 & 2 & 5 & 9 & & 2 & 2 & 2 & 6 \\
\hline Opportunity to learn/practice active play & & 2 & 4 & 0 & 6 & & 1 & 4 & 4 & 9 \\
\hline \multicolumn{11}{|l|}{ What did you dislike about the badminton?-3 wks } \\
\hline Nothing & & 7 & 2 & 4 & 13 & & 6 & 1 & 6 & 13 \\
\hline Too much skill/drill - too little play & & 2 & 4 & 4 & 10 & & 1 & 4 & 4 & 9 \\
\hline Stopping so often & & 0 & 4 & 1 & 5 & & 1 & 3 & 0 & 4 \\
\hline Too long & & & & & & & 2 & 0 & 1 & 3 \\
\hline \multicolumn{11}{|l|}{$\begin{array}{l}\text { Are you any better at badminton now than } 3 \text { weeks } \\
\text { ago? How? }\end{array}$} \\
\hline \multicolumn{11}{|l|}{ Mid 3 weeks ago: } \\
\hline Specific skills & & 8 & 7 & 11 & 26 & & & & & \\
\hline General knowledge \& ability at badminton & & 6 & 8 & 7 & 21 & & & & & \\
\hline Strategies & & 2 & 5 & 1 & 8 & & & & & \\
\hline
\end{tabular}


Post 3 weeks ago:

Specific skills

General knowledge \& ability at badminton

Strategies

$\begin{array}{rrlr}7 & 5 & 2 & 14 \\ 5 & 5 & 10 & 20 \\ 1 & 4 & 2 & 7\end{array}$

Post 6 weeks ago:

Specific skills

General knowledge \& ability at badminton

Strategies

Why will you play badminton again in the future?

Enjoy playing it?

Good recreational activity

Have access to equipment

Why will you not play badminton in the future?

Didn't enjoy it

No access to equipment

Not a popular sport

How was this physical education class different

from other physical education classes?

Spent longer on one activity

Learned something (was taught throughout

the unit)

Related to research project

Not different

Small class

New activity

Note . Con.$=$ control group. Tact.$=$ tactical group . Comb. $=$ combination group 
In general, these students enjoyed participating in sports (preunit $M=4.91$ ), felt that participating in sports was important to them (preunit $M=4.40$ ), and believed that they were good at sports (preunit $M=4.50$ ). Although the ratings suggest that these students enjoyed playing badminton (preunit $M=4.70$ ), the ratings also indicate that playing badminton was not especially important to them (preunit $M=3.23$ ), including the experimental groups after the unit.

\section{Open-Ended Responses}

Sports in General. The reasons the students gave for choosing a particular Likert rating of their enjoyment of, the importance of, and ability at sports in general differed little among the groups interviewed. They also differed little pre- to postunit. The students said that they enjoyed participating in sports because they liked sports/sports were fun, liked the teamwork and social interactions connected with sports, liked the fitness and health benefits gained from sports, and enjoyed the challenge of competition in sports. There were, however, a few differences between males and females. The most common reason given by all students for not enjoying participating in sports was that they perceived they had low ability at sports. Males mentioned the fitness benefits more often than females, while females mentioned the social benefits more often.

The main reason these students gave why sports were important to them was the fitness and health benefits derived from participating in sports. They also valued the fun they had while participating in sports, the social aspects of sports, and the fact that sports gave them something to do. These reasons did not differ between males and females. The few students who rated sports as not important generally agreed that sports were just not as valuable as other things they could be doing.

The primary reasons these students gave for believing they had high ability in sports were (a) they gave high effort at sports, (b) they had naturally high athletic ability, and (c) they had lots of experience playing sports. However, females were more likely to give their playing experience as a reason for their high ability, whereas males were more likely to talk about their natural athletic ability. The two main reasons given by students for saying they had low general sports ability were that they lacked natural athletic ability and that they had little experience with sports.

Badminton. Some group, gender, and pre- to postunit differences emerged in the students' reasons for choosing a particular Likert rating of their enjoyment of, the importance of, and their ability at badminton. Both before and after the unit, the most common reason given by all students for enjoying playing badminton was that badminton is generally a fun sport. The students also enjoyed badminton because it is similar to other sports and because they liked the skills and strategies of badminton. After the unit, however, more students in the experimental groups could identify what they liked about badminton, as the number of these students who said they liked the skills and strategies of badminton increased; no control group students gave such specific responses. Furthermore, after the unit, many students in the combination group said they enjoyed badminton because of the social interactions possible and because they learned from the teacher. Many students in the tactical group said after the unit that they enjoyed badminton because they liked the challenge of the game. 
The main reasons both before and after the unit for not enjoying badminton were because they lacked experience playing badminton, had low ability at badminton, and did not like the skills/strategies of badminton. Before the unit, these responses came from all groups; after the unit, these responses came almost exclusively from the control group. Both before and after the unit, males were more likely than females to give lack of playing experience as a reason for not enjoying badminton.

The primary reason given by all students, both pre- and postunit, for saying that playing badminton was important was that badminton is fun and generally enjoyable to them. Before the unit, several females referred to the social aspects of playing badminton as reasons for its importance. After the unit, these social reasons were not mentioned, but females frequently stated that badminton was important because they would be graded on their performance. Males did not talk about social aspects or grades. The reasons given before the unit for saying that playing badminton was not important were similar for the groups, but differed for males and females. Males said it was not important because they did not have experience playing the sport, whereas females said it just was not as important as other things (low relative value). After the unit, the most common reason students in the control group gave for the low importance of badminton was their lack of playing experience. Interestingly, this response came primarily from females. Students in the experimental groups said that badminton was just not as important as other things.

Although males and females did not differ in their reasons for their chosen badminton ability level, there were some differences between the groups from preto postunit. Prior to the unit, the four groups gave similar reasons for saying they were good at badminton: They had high natural athletic ability and had experience playing badminton. After the unit, the main reason given by all students was still their high athletic ability. At the end of the unit, however, the students in the experimental groups also said their high badminton ability was because they learned about badminton from their teacher in class. The main reason given by all students before the unit for saying they had low badminton ability was because they had little experience playing badminton. After the unit, this reason came only from the control group. The two students in the experimental groups who said they had low badminton ability said it was because they lacked natural athletic ability.

The 6-Week Instructional Experience. When the 32 students (4 students were not interviewed) in the three experimental groups were asked at midunit and after the unit if they thought they were better at badminton than before the unit, all students said yes. Only 2 male students did not believe their badminton skills had improved further from midunit to postunit. The most common improvement cited by all three groups was in their general knowledge and ability at badminton. Skill and tactical group students also often named specific skills in the midunit and postunit interviews when asked how they improved. Although the combination group also named specific skills at midunit, they rarely mentioned these in their postunit responses. Tactical students frequently said their abilities to use strategies improved, a response rarely given by the skill and combination groups. This response came primarily from males; females rarely mentioned strategy improvement. 
The main reason given by all three groups for their improvement from before the unit to midway through the unit and from midunit to postunit was because they practiced and played badminton in class. The tactical group also said they improved because they learned about badminton from their teacher. When asked after the unit why they thought they were better at badminton than 6 weeks ago, students in the skill and combination groups gave two main reasons: They had practiced and played badminton in class, and they had learned about badminton from the teacher. The strategy group did not give playing experience as a reason for improvement; their most frequent reason was they had learned from the teacher. The reasons for improvement did not differ for males and females.

When asked what they liked about their badminton class at both mid- and postunit, the most common response given by all three groups was the competition and game play parts of the classes. This response was given by slightly more males than females, especially at midunit. Several students in all three groups also liked the social aspects of the class (being with friends, interacting with others) and the sport of badminton itself. Females, however, were more likely than males to name social aspects as well as the teacher as things they liked about the class. At both mid- and postunit, several strategy students also said that they liked learning about badminton and practicing before they played games; some combination groups said they liked practicing before they played games postunit but not midunit, and no students in the skill group said they liked pregame practice.

The things these students disliked about their badminton classes did not differ for males and females or from mid- to postunit. Many students, especially those in the skill and combination groups, said they disliked nothing about their badminton classes. However, a large number of students, especially combination and tactical students, said there was too much skill/drill practice and not enough game play. Several tactical students also disliked stopping their practice so often to listen to the teacher. Only 2 skills students and 1 combination student disliked spending so long on one activity.

When asked if they would play badminton again in the future, 27 of these 32 experimental students said yes. Four males and 1 female said no, and these students came from all three experimental groups. Students said they would play again because they enjoyed the sport and felt it was a good recreational activity. Access to the proper equipment was a concern of students who said yes and no: Students would play again if the proper equipment were available, and students would not play again because they did not have the needed equipment. Only 2 students said they would not play again because they did not enjoy badminton.

The two most commonly named features that made this class different from previous physical education classes was that more time was spent on one activity and that the students were taught things throughout the unit. Most of the regular physical education units in this school were taught so that practice of skills for a few days was followed by game play for the rest of the unit. All 32 experimental students said they liked physical education classes that tried to teach them something, primarily because they enjoyed learning about and improving their sport skills. All but two of the students preferred 6-week units over 3-week units because they liked learning more about the complete game. The one male and one female who favored shorter units said that they wanted to know just the basics and that they got bored with long-term things. 


\section{Discussion}

It is not uncommon in the literature for practicing physical educators to talk about and accept the fact that high school programs are not effective (Locke, 1992; Siedentop, 1992). Carlson (1995) suggested in one study that $20 \%$ of the students do not enjoy physical education. The students participating in this study tell a different story. They liked participating in sports, most did so on a regular basis, and the reasons they gave for participating are consistent with the reasons we teach sport: fun, teamwork, social interaction, fitness, health benefits, and challenge. These reasons are also consistent with other studies investigating student perceptions of outcomes in physical education programs (Tannehill \& Zakrajsek, 1993). The level of importance students attached to both sport and badminton was also consistent with the literature. Almost all of these students had a healthy perspective of the importance of sport in their lives. There were a few individuals who responded that sport was to be an occupation for them, but most students saw sport as a contributor to their lives (consistent with why they saw sport as being important) but not the essence of how they defined themselves.

The results of these interviews also support the literature that seems to reflect a real cultural hierarchy in the type of sport identified as important (Luke \& Sinclair, 1991; Tannehill \& Zakrajsek, 1993). Boys, in particular, did not attach as football, baseball, and soccer. The reasons these students gave for not participating in sport outside of the physical education class and not being good at sport are also consistent with conventional wisdom: a lack of experience and a lack of ability were by far the most common reasons for not being a participant (Feltz \& Brown, 1984).

At the midunit interview and at the 6-week interview, all of the students in specifically how they had gotten better. The fact that boys almost consistently talked about how they had gotten better at strategies and the fact that ins developmental their ability to smash relevant may provide some insight into the devably ever get to aspects of becoming good at sport. In most sports, few such as the point where they can use skillful offensive shith being dents closely identified enjoyment of the game with being skillful, and they at-

Few students could respond specifically to the probe that asked them to identify what they did not like about the classes they participated in. The few that did respond identified the teacher stopping game play or practicing rather than playing as being what they did not like about their classes. These responses, however, did not come from the skill group. All teachers were very positively received. Students could identify that this unit experience was different from their normal physical education class because it was longer and because they were "taught throughout the unit." Normally, units for these students would involve a few days of skill practice and then game play. They also responded positively to the idea of having 6-week rather than 3-week units and almost unanimously said they would play the game again.

The results of this study do not identify any affective superiority for a particular approach to teaching a sport, with perhaps the exception that the combination group perceived slightly greater improvement over the unit than the other two 
experimental groups. The implications of the affective results of this study support the idea that teachers can teach a physical education class with the goal of developthe desire to participate with both exputing to affective goals. Students associate proach tendencies toward participatience and skill in an activity. Positive aplikely to be the product of the increased badminton, as well as other sports, are students developed. If developing an axperience and skill in sport that these education programs, then the developme lifestyle is a major goal of physical sport are likely to be major contributors (Carlson, 1995).
There are many aspects oxperiences with that would be more associated affective development not addressed in this study and respect for differences among standards related to developing responsibility clear, however, that the experieng people (NASPE, 1995, Standards 5 and 6). It is effective learning environment did have a major affective effect. A positive and able for these students. Thent was created, and participation was fun and enjoywith environments that have concepts are, unfortunately, not always associated dents were aware of the intrinsc major intent to produce skillful performance. Stutified ideas such as challenge, competition, anticipation in this unit and idenacteristics of that experience. 